\title{
Development of a stress scale for pregnant women in the South Asian context: the A-Z Stress Scale
}

A. Kazi, ${ }^{1}$ Z. Fatmi, ${ }^{1}$ J. Hatcher, ${ }^{1}$ U. Niaz ${ }^{2}$ and A. Aziz'

$$
\begin{aligned}
& \text { إعداد سلم لقياس الكَرْب لدى الحوامل في بيئة شرقَ - آسيوية }
\end{aligned}
$$

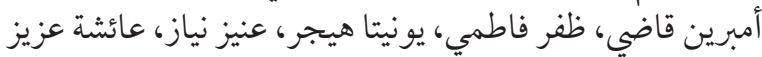

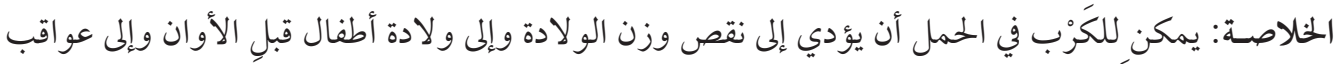

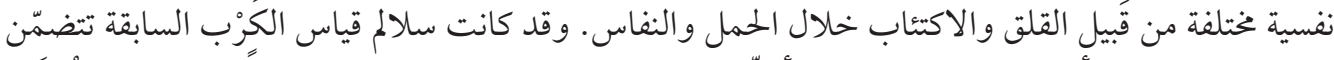

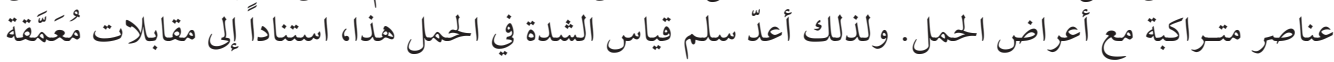

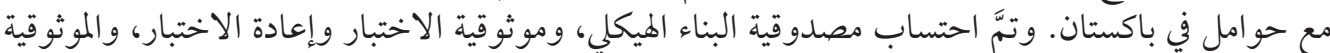

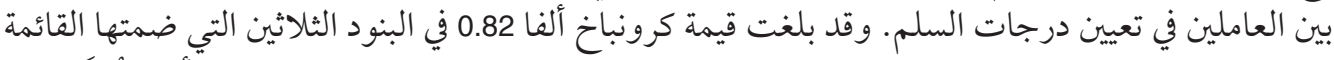

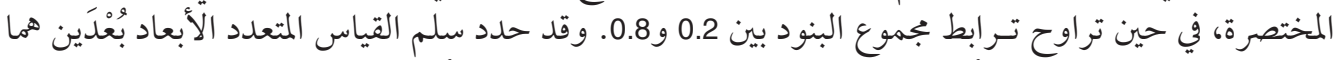

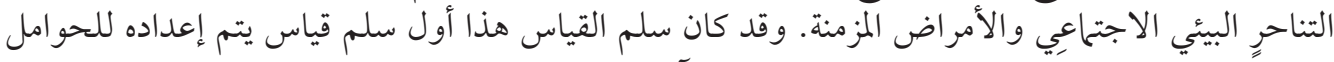

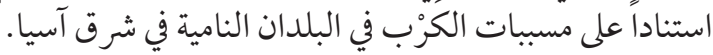

ABSTRACT Stress in pregnancy can lead to low-birth-weight and preterm babies and to psychological consequences such as anxiety and depression during pregnancy and the puerperium. Previous scales to measure stress contain items that overlap with the symptoms of pregnancy. A stress scale was developed based on in-depth interviews with pregnant women in Pakistan. Construct validity, test-retest reliability and inter-rater reliability were carried out. Cronbach alpha was 0.82 for the 30 short-listed items, with item-total correlations of $0.2-0.8$. Multidimensional scaling determined 2 dimensions: socioenvironmental hassles and chronic illnesses. This was the first scale developed for pregnant women based on stressors in a developing country in South Asia.

Mise au point d'une échelle du stress pour les femmes enceintes dans le contexte de l'Asie du Sud : l'échelle « A-Z »

RÉSUMÉ Le stress pendant la grossesse peut entraîner un faible poids de naissance et une prématurité du bébé et peut avoir des conséquences psychologiques (anxiété, dépression) pendant la grossesse et la période puerpérale. Jusqu'à présent, les échelles de mesure du stress comprenaient des items qui coïncidaient avec les symptômes de la grossesse. Une nouvelle échelle a donc été élaborée à partir d'entretiens approfondis avec des femmes enceintes au Pakistan. On a ensuite testé la validité de construction, la fiabilité du test-retest et la fiabilité inter-juges. L'alpha de Cronbach était de 0,82 pour les 30 items présélectionnés, avec des corrélations entre les items et le score total comprises entre 0,2 et 0,8 . La mesure multidimensionnelle a permis de déterminer deux dimensions : les facteurs de stress socioenvironmentaux et les maladies chroniques. Cette échelle est la première échelle concernant les femmes enceintes et s'appuyant sur les causes de stress dans un pays en développement d'Asie du Sud.

${ }^{1}$ Department of Community Health Sciences, Aga Khan University, Karachi, Pakistan (Correspondence to A. Kazi: ambreen.kazi@aku.edu).

${ }^{2}$ Psychiatric Clinic and Stress Research Centre, Karachi, Pakistan.

Received: 14/07/06; accepted: 09/11/06

المجلة الصحية لشرق المتوسط، منظمة الصحة العالمية، المجلد الخامس عشر، العلد Y، 9 +. 


\section{Introduction}

Psychosocial stress is a risk factor for physical and psychological illness [1-3]. Social adversities contribute greatly to a high prevalence of psychological illness among women in developing countries [4-6]. Stress factors may range from a poor relationship with the husband to various social issues in the environment [6-9]. A high prevalence of psychological illness has been found among pregnant women [10-12]. Studies show that stress during pregnancy can contribute to adverse pregnancy outcomes such as low birth weight and preterm delivery [12-15]. Measurement of psychological health in pregnant women is a challenging task.

Previous scales were developed based only on psychological and somatic symptoms rather than the stressors themselves, i.e. on the responses to stress rather than the factors perceived as stressful by the woman [16]. Moreover, many pregnant women express neurological disorders as somatic complaints such as dyspepsia, body aches and loss of appetite [17]. Such symptoms overlap with the normal symptoms of pregnancy [17]. Our aim was to develop an appropriate and comprehensive scale based on stressors for measuring stress among pregnant women in a developing country.

\section{Methods}

This study was conducted from July 2003 to September 2004 in Karachi, Pakistan. The city of Karachi has a population of 14 million with considerable socioeconomic and ethnic diversity. Literacy among females is $57 \%$ and $3.2 \%$ are employed [18].

\section{Phase 1: development of the scale}

In Phase 1 of the study the framework of the scale was set into the South Asian context by conducting interviews with experts and pregnant women. Items for the scale were selected using Thurstone's scaling method of equal-appearing intervals [19].

For development of the initial construct, textbooks, measuring instruments and published literature about stress measurement were reviewed. Next, interviews were conducted with 25 experts, including psychologists, psychiatrists, gynaecologists, sociologists, social workers and researchers.

From the initial construct, a semistructured guideline was developed and 79 in-depth interviews were conducted with pregnant women. A list of stressors (items) was gathered asking about "difficulties" or "stressful situations". Women were selected from 6 hospitals (public and private) and 2 communities to include a socioeconomically diverse population of different parity and trimester (Table 1).

Interviews were continued until no new stressors were identified (sample to redundancy).

Initially, a total of 235 items were identified. Using Thurstone scaling, items were ranked by 25 experts on a $0-10$ scale of severity (0 as "no stress" and 10 as "maximum stress"). The median and interquartile range were calculated for each item. Items were arranged in ascending order of median value, and within each median value items were arranged in descending order of interquartile range. In this way, 78 items were selected at equal distances of median and interquartile range. Before being excluded, each item was assessed for content, redundancy and understandability. Selected items were pretested on an additional sample of 70 pregnant women.

\section{Phase 2: validation and reliability of the scale}

For the validity and reliability studies of the scale, pregnant women were selected from 4 hospitals and 2 communities in Karachi 
Table 1 Sociodemographic profile of pregnant women in phase $1(n=79)$ and phase $2(n=342)$ of the study in Karachi Pakistan

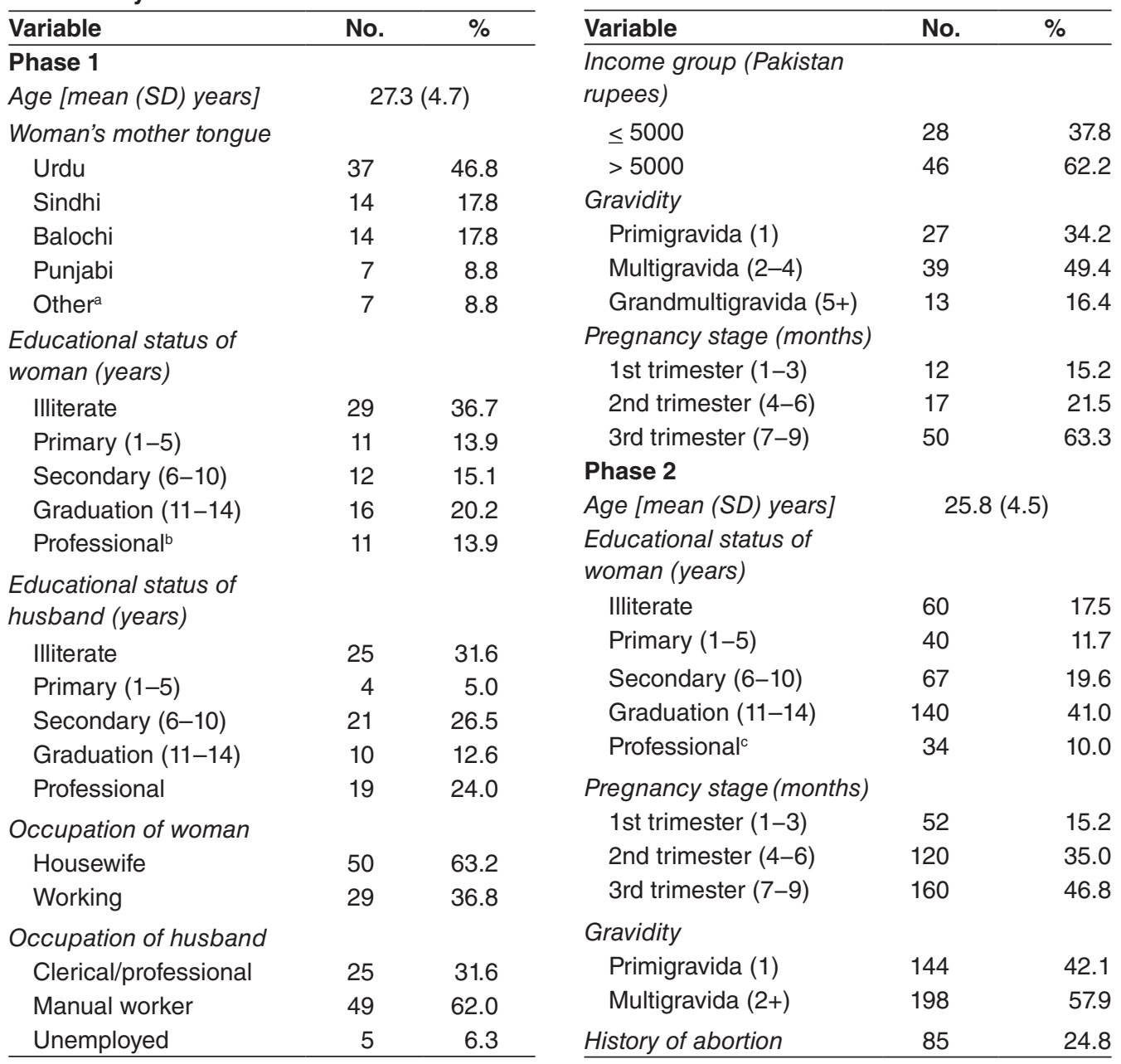

Missing numbers are due to non-response to that item. alncludes Pushto, Memon, Gujarati, Bengali.

${ }^{b}$ Includes health professionals, engineers, teachers and managers.

belonging to low, medium and high socioeconomic groups (Table 1).

Female psychologists and sociologists were trained to conduct the interviews. If any item was perceived as a stressor by a woman during the previous 1 month it was marked as positive. On average, each interview lasted for 45 minutes. The refusal rate to participate was $<5 \%$.
Studies conducted in Pakistan on social factors related to depression among mothers and pregnant women supported the construct of the scale and suggested that stress and depression were overlapping concepts. Concurrent validity was measured by comparing the A-Z Stress Scale with the translated (Urdu language) version of the Center for Epidemiological Studies-Depression 
(CES-D) Scale. CES-D is a multicultural, validated instrument that has been used in India and Bangladesh [11,20,21]. It consists of 20 items. An individual score for a woman on the CES-D scale may range from $0-60$. A cut-off $\geq 16$ has been recommended to diagnose depression disorder [22]. The 2 scales were administered to a group of 292 pregnant women by separate interviewers (blinding).

Inter-rater reliability was examined in a sample of 50 pregnant women. Two interviewers administered the $\mathrm{A}-\mathrm{Z}$ Stress Scale separately during the same visit.

Test-retest reliability was tested in a separate sample of 43 pregnant women. The scale was administered twice with an interval of 1 week by the same interviewer to the same pregnant women.

\section{Ethical issues}

Approval for the study was taken from the Aga Khan University ethical review committee. Informed written consent was taken from the women before the interviews. Life histories taken were kept anonymous. Counselling was provided to depressed women by the psychologist or they were referred for further management. The data were analysed with identifier numbers for each woman to maintain confidentiality.

\section{Analysis}

The items that were perceived as stressors during the previous month (marked as positive) were assigned weightings (median rank using Thurstone's method). The final items were selected based on item-total correlation.

Identified items were analysed for their dimensions by the multidimensional scaling method, calculating the S-STRESS value and mean square of distances.

Cronbach alpha values for the selected items were calculated to determine the internal consistency of the scale. Cronbach alpha was also calculated for the trimesters of pregnancy, parity and socioeconomic status.

The analysis examined associations between total scores on the CES-D and total scores of the A-Z Stress Scale items. The inter- and intra-class correlation coefficients for the total scale score among the same and different observers were examined.

\section{Results}

The final 30 items of the A-Z Stress Scale are shown in Table 2. The items consisted of family-related concerns (husband, children, in-laws and parents), socioeconomic concerns and pregnancy-related concerns. The maximum possible score for the A-Z Stress Scale was 179 . The mean weighted score for the sample of pregnant women was 42.6 (standard deviation 29.5; range 0-142).

The item-total correlations for each item ranged between $r=0.2$ and $r=0.8$ (Table 2). Cronbach alpha for the A-Z Stress Scale was 0.82 . Cronbach alpha coefficients ranged from 0.75 to 0.86 across different levels of parity, trimester and socioeconomic status (Table 3 ).

Two dimensions of the scale were determined by multidimensional scaling: socioenvironmental hassles and chronic illnesses (Figure 1). The S-STRESS value for the scale was 0.10 at 2 dimensions and the squared correlation of the distances was 0.96 .

Inter-rater reliability for the scale was $r$ $=0.91(P<0.01)$. The stability of the scale over time (test-retest reliability) was 0.86 $(P<0.01)$.

The total weighted A-Z Stress Scale score was moderately correlated with the total CES-D score $(r=0.56, P<0.00)$. The total weighted score of the applicable items represents the stress level for an individual woman and the score is dealt with on a con- 
Table 2 Median values and item-total correlation of stressor items for pregnant women $(\boldsymbol{n}=\mathbf{3 4 2})$

\begin{tabular}{|c|c|c|c|}
\hline Item & Stressor item & $\begin{array}{c}\text { Median } \\
\text { (weighting) }\end{array}$ & $\begin{array}{l}\text { Item-total } \\
\text { correlation }\end{array}$ \\
\hline$\overline{1}$ & Concern about gaining supremacy among in-laws & 4 & 0.31 \\
\hline 2 & Concern about missing own parents & 5 & 0.30 \\
\hline 3 & Concern about rented home & 5 & 0.40 \\
\hline 4 & Concern about in-laws/guests visiting at odd times & 5 & 0.28 \\
\hline 5 & Concern about access to husband's money & 7 & 0.39 \\
\hline 6 & Concern about not having freedom to make decisions & 5 & 0.41 \\
\hline 7 & Concern about husband's inattention & 6 & 0.34 \\
\hline 8 & Concern about owing money & 6 & 0.39 \\
\hline 9 & Concern about household responsibilities & 6 & 0.50 \\
\hline 10 & Concern about husband's worries & 7 & 0.34 \\
\hline 11 & Concern about verbal abuse by husband & 7 & 0.37 \\
\hline 12 & Concern about husband's unstable job & 7 & 0.37 \\
\hline 13 & Concern about husband's unemployment & 8 & 0.29 \\
\hline 14 & Concern about insufficient money for buying the house & 6 & 0.43 \\
\hline 15 & Concern about increases in the prices of everyday goods & 6 & 0.42 \\
\hline 16 & Concern about looking after the children & 5 & 0.37 \\
\hline 17 & Concern about inaccessibility of health care & 6 & 0.34 \\
\hline 18 & Concern about delay in household work due to pregnancy & 5 & 0.47 \\
\hline 19 & Concern about unwanted pregnancy & 7 & 0.30 \\
\hline 20 & Concern about waking up late due to pregnancy & 5 & 0.28 \\
\hline 21 & Concern about less socialization due to pregnancy & 4 & 0.34 \\
\hline 22 & Concern about giving birth to a girl child & 6 & 0.34 \\
\hline 23 & Concern about appearance of unborn baby & 4 & 0.20 \\
\hline 24 & Concern about having a major fight with relatives & 7 & 0.20 \\
\hline 25 & Concern about too many people living in the house & 5 & 0.23 \\
\hline 26 & Concern about having a major fight with in-laws & 8 & 0.28 \\
\hline 27 & Concern about anyone's illness in the original family & 6 & 0.31 \\
\hline 28 & Concern about children's illness & 9 & 0.35 \\
\hline 29 & Concern about feeling unwell during pregnancy & 5 & 0.34 \\
\hline 30 & Concern about husband's major illness or injury & 7 & 0.24 \\
\hline \multicolumn{2}{|c|}{ Maximum score } & 179 & \\
\hline
\end{tabular}

tinuum basis, with higher scores reflecting more stress.

\section{Discussion}

Stress during pregnancy may lead to adverse physical outcomes such as preterm birth and low-birth-weight babies and also to psychological consequences for the women. Stress is a precursor to anxiety and depression during pregnancy and is related to puerperal depression among women. Women with stress have a higher prevalence of anxiety and depression during pregnancy and the puerperal period $[1-3,7,11,12]$. 
Table 3 Cronbach alpha internal consistency of the scale items by parity, trimester and socioeconomic status (SES) of pregnant women

\begin{tabular}{lcc}
\hline Variable & $\begin{array}{c}\text { No. of } \\
\text { women }\end{array}$ & $\begin{array}{c}\text { Cronbach } \\
\text { alpha }\end{array}$ \\
\hline $\begin{array}{l}\text { Total } \\
\text { Gravidity }\end{array} \quad 292$ & 0.82 \\
$\quad$ Primigravida & 89 & 0.80 \\
$\quad$ Multigravida & 203 & 0.82 \\
Pregnancy stage & & \\
$\quad$ 1st trimester & 42 & 0.81 \\
$\quad$ 2nd trimester & 100 & 0.81 \\
$\quad$ 3rd trimester & 121 & 0.82 \\
SES & & \\
$\quad$ Lower & 100 & 0.86 \\
$\quad$ Middle & 121 & 0.78 \\
$\quad$ High & 71 & 0.75 \\
a Some data missing for this category.
\end{tabular}

${ }^{a}$ Some data missing for this category.

This is the first comprehensive scale developed to measure stress among pregnant women in the South Asian context. Existing scales have relied on items measuring psychological and somatic symptoms that are common during pregnancy. Therefore their utility for identifying stress among pregnant women is limited [23]. Existing scales also lack specificity because they have been developed in different sociocultural settings. Furthermore, these scales have simply been translated before use, without any validation studies [24].

The face and content validity of the $A-Z$ Stress Scale were established by assessing its content with the help of the literature and consensus with experts. Thurstone's scaling method was used as a guideline to select the items while the researchers' judgement about content and completeness were also used as essential criteria to select or drop any item [19]. The item contents consisted initially of "daily hassles", "life events" and "pregnancy-related hassles"; therefore, the A-Z Stress Scale is a comprehensive scale for stress incorporating all these concepts in one scale. We also found that life events were rare and were therefore less important for measuring stress. This has also been suggested by other researchers in the field; that life events were distal measures whereas daily hassles were proximal measures of stress and, due to their chronic nature, have a greater impact [25]. Existing scales are either based only on items of daily hassles or on life events separately $[25,26]$.

Multidimensional scaling was used to determine the dimensions of the scale. This method identified 2 dimensions of the $\mathrm{A}-\mathrm{Z}$ Stress Scale: socioenvironmental hassles and chronic diseases. The S-STRESS value of this model was 0.10 , which is considered excellent. The squared correlation of the distances of the scale was 0.96 , i.e. variation explained by the scale is $96 \%$ [27]. Socioenvironmental hassles on the A-Z Stress Scale related to household environment and relations with husband, children, in-laws and parents. Socioeconomic concerns, household chores, adverse life events, chronic illness of relatives and pregnancy-related concerns were also identified as important stressors. Studies conducted in Pakistan on the social factors related to depression among mothers and pregnant women support the construct of the scale [4-7].

Each item has to be interpreted in 2 ways. First, whether the item was applicable to the individual pregnant woman's situation in the previous month and, second, whether that item raised concern for that woman. For example, item 2 (concern about missing own parents) raises 2 issues: first, whether the woman lives away from her parents, and, secondly, whether it raises concern for the individual woman. Therefore, the item captures both the situation as well as the perception of the woman, which makes this study more in-depth than others conducted on this subject $[6,7,9,27]$. 


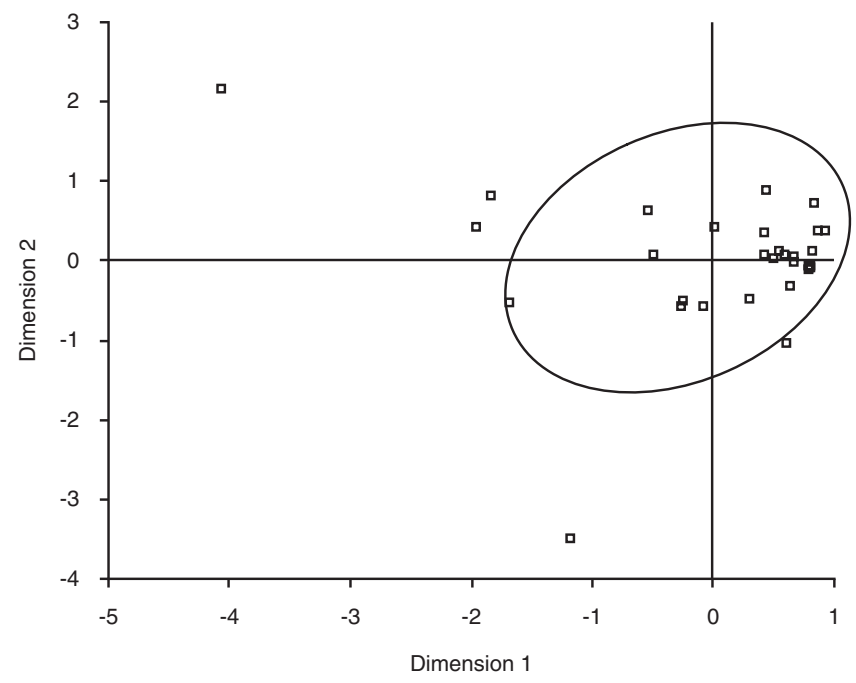

Figure 1 Dimension identification with the multidimensional scaling model. Items within the circle relate to socioenvironmental hassles (items 1-26 in Table 2); items outside the circle relate to chronic illnesses (items $27-30$ in Table 2)

Various procedures were used to establish the reliability of the scale. In the first instance, identification of stress items was based on responses from heterogeneous samples (from multiple hospitals and communities), ensuring that subject variability in the society was reflected in the scale. Empirical evidence for construct validity was established between items by keeping items having item-total correlation between $r=0.2$ and $r=0.8$ [28]. Cronbach alpha for the scale, which provides an average of all possible split-half reliabilities for the scale in question, was within the recommended range [28]. The A-Z Stress Scale also showed good stability and applicability across different socioeconomic status, trimester and parity.

Test-retest reliability for the scale items was respectably high, suggesting that the scale is reliable over time. We evaluated test-retest reliability after a 1 -week interval, which is adequate for most scales [28].
The A-Z Stress Scale is administered by interview, with a "yes/no" format, and can be administered by interviewers with only 10th grade education. For the present scale, the inter-rater reliability of stressors was high, suggesting that if the scale was administered by different interviewers, its understandability would remain the same.

A measure must also be simple to use. Most women in South Asia are not educated, so the applicability of a self-administered assessment scale would be very limited. We judged that response options using rank ordering or Likert scales were not applicable in this setting.

In addition, the discriminant validity of the A-Z Stress Scale was assessed by examining its association with the CES-D [28]. It should be noted that, while depression and stress may be overlapping concepts, they should not be considered equivalent to each other, a fact that is demonstrated by in the moderate correlation between A-Z Stress 
Scale and CES-D total scores. It may also suggest that stress and depression lie on the same continuum [2]. The A-Z Stress Scale does not diagnose or label any woman as stressed or stress-free. Total scores can be utilized for suggesting level of stress.

We also recommend that further predictive studies validate this scale by examining associations of stress with pregnancy outcome such as premature labour and low birth weight and the psychological well-being of women such as anxiety and depression. These predictive studies would determine stress levels (scores) that may reliably forecast adverse pregnancy and psychological outcomes. Further studies might also consider delineating factors relevant to the development of a more general stress scale for women who are not pregnant.

Stressor items could be used by gynaecologists to identify women with socioenvironmental problems. Scale items have identified potential areas of counselling for pregnant women to prevent stress and depression. Future studies can be conducted using this scale to look at the effect of stressors on low birth weight and preterm labour.

The scale can be used for pregnant women only and is based on the women's perceptions. Stressors may vary during the pregnancy; therefore it is advisable to administer the scale multiple times during pregnancy. The validity of the scale over time has been tested for 1 week only.

In conclusion, this study identified a set of psychosocial stressors among pregnant women in the South Asian context. The A-Z Stress Scale has 2 dimensions and shows good evidence of validity and reliability. Most stressors are related to socioenvironmental hassles and chronic diseases. The A-Z Stress Scale is a potentially important tool that can be used to improve the reproductive health of women. It could readily be utilized by clinicians, researchers and social scientists working for the wellbeing of women in South Asia.

\section{References}

1. Pasnau RO et al., eds. Comprehensive textbook of psychiatry, 5th ed. Baltimore, Williams and Wilkins, 1989:1231-49.

2. Carson RC, Butcher JN, Mineka S. Abnormal psychology and modern life. In: Stress and adjustment disorders, 10th ed. New York, Longman, 1998:Ch. 4.

3. Comer RJ, ed. Fundamentals of abnormal psychology, 3rd ed. New York, Worth Publishers, 2002.

4. Niaz U. Women's mental health. Karachi, Pakistan Psychiatric Society, 2000 (Monograph Series II).

5. Fikree FF, Bhatti LI. Domestic violence and health of Pakistani women. International journal of gynaecology and obstetrics, 1999, 65:195-201.
6. Husain N, Creed F, Tomenson B. Depression and social stress in Pakistan. Psychological medicine, 2000, 30:395-402.

7. Mumford DB et al. Stress and psychiatric disorder in urban Rawalpindi. Community survey. British journal of psychiatry, 2000, 177:557-62.

8. Niaz U. Overview of women's mental health in Pakistan. Pakistan journal of medical sciences, 2001, 17:203-9.

9. Rabbani F, Raja FF. The minds of mothers: maternal mental health in an urban squatter settlement of Karachi. Journal of the Pakistan Medical Association, 2000, 50:306-12.

10. Bennett HA et al. Prevalence of depression during pregnancy: systematic re- 
view. Obstetrics and gynecology, 2004, 103(4):698-709.

11. Gavin NI et al. Perinatal depression: a systematic review of prevalence and incidence. Obstetrics and gynecology, 2005, 106(5):1071-83.

12. Rahman A, Iqbal Z, Harrington R. Life events, social support and depression in childbirth: perspectives from a rural community in the developing world. Psychological medicine, 2003, 33(7):1161-7.

13. Dole $\mathrm{N}$ et al. Maternal stress and preterm birth. American journal of epidemiology, 2003, 157:14-24.

14. Wadhwa PD et al. Stress, infection and preterm birth: a biobehavioural perspective. Paediatric and perinatal epidemiology, 2001, 15(Suppl. 2):17-29.

15. Mulder EJ et al. Prenatal maternal stress: effects on pregnancy and the (unborn) child. Early human development, 2002, 70(1-2):3-14.

16. McDowell I, Newell C. Measuring health: a guide to rating scales and questionnaires, 2nd ed. New York, Oxford University Press, 1996:10-46.

17. Stotland NL. Psychiatric issues. In: Barron WM, Kindheimer MD, eds. Medical disorders during pregnancy, 2nd ed. St Louis, Mosby, 1995.

18. Population and housing census. Islamabad, Pakistan, Government of Pakistan, 1998.

19. Trochim W. Research methods knowledge base. Web Centre for Social Research Methods, Cornell University [online textbook] (http://www.socialresearchmethods.net/kb/, accessed 20 July 2008).

20. Jain $D$ et al. Violence against women in India: evidence from rural Maharashtra, India. Rural remote health, 2004, 4(4):304.
21. Tsutsumi A et al. Depressive status of leprosy patients in Bangladesh: association with self-perception of stigma. Leprosy review, 2004, 75(1):57-66.

22. Radloff LS. The CES-D scale: a self-report depression scale for research in the general population. Applied psychological measurement, 1977, 1:385-401.

23. Ali BS et al. Development of an indigenous screening instrument in Pakistan: the Aga Khan University Anxiety and Depression Scale. Journal of the Pakistan Medical Association, 1998, 48:261-5.

24. Taj R, Sikander KS. Effects of maternal depression on breast-feeding. Journal of the Pakistan Medical Association, 2003, 53:8-11.

25. Huizink AC et al. Multidimensional models of prenatal distress in normal risk pregnancy. In: Huizink AC. Prenatal stress and its effect on infant development [dissertation]. Utrecht, The Netherlands, University of Utrecht, 2003:Ch. 7 (http://www.library.uu.nl/digiarchief/dip/ diss/1933819/c7.pdf, accessed 20 July 2008).

26. Holmes and Rahe scale of life events. Chicago, University of Illinois at Chicago Department of Psychiatry [website] (http:// www.psych.uic.edu/education/courses/ behav_science1999/adultdeveopment99/ tsld012.htm, accessed 20 July 2008).

27. Borgatti SP. Multidimensional scaling [website] (http://www.analytictech.com/ borgatti/mds.htm, accessed 20 July 2008).

28. Streiner DL, Norman GR. Health measurement scales: a practical guide to their development and use, 2nd ed. New York, Oxford University Press, 1994. 